\title{
Ruptured middle cranial fossa arachnoid cysts after minor trauma in adolescent boys presenting with subdural hygroma: two case reports
}

\author{
Mohammad Farouq Hamidi ${ }^{1}$ and Hidayatullah Hamidi ${ }^{*}$ (1)
}

\begin{abstract}
Background: Intracranial arachnoid cysts are common, cerebrospinal fluid-filled, innocent lesions that are usually detected incidentally on brain imaging. They may rupture and complicate due to subdural hematoma or hygroma after minor trauma.

Case summary: Authors present two cases of ruptured middle cranial fossa arachnoid cysts in adolescent (12-yearold and 15-year-old) Afghan boys presenting with subdural hygroma after minor trauma.

Conclusion: Imaging work-up is necessary for symptomatic patients following minor head trauma as incidentally detected ruptured intracranial arachnoid cysts can be responsible for the symptoms.
\end{abstract}

Keywords: Arachnoid cyst, Subdural hygroma, Ruptured arachnoid cyst, Case report

\section{Introduction}

Intracranial arachnoid cysts (IACs) are common, cerebrospinal fluid (CSF)-filled, innocent, congenital, benign, extra-axial intracranial lesions that are usually detected incidentally on brain imaging [1]. They may rupture and complicate due to subdural hematoma or hygroma after minor trauma. Imaging work-up is necessary for patients with signs and symptoms of increased intracranial pressure following head trauma.

\section{Case presentation}

Case 1

A previously healthy 12-year-old Afghan boy came to clinic complaining of a persistent headache for the last 20 days after minor head trauma while playing football.

*Correspondence: Hidayatullah.hamidi@gmail.com

2 Radiology Department, French Medical Institute for Mothers and Children (FMIC), Kabul, Afghanistan

Full list of author information is available at the end of the article
The patient also had nausea and vomiting for 4 days after trauma, which then stopped. No history of unconsciousness was documented. The Glasgow Coma Scale (GCS) of the patient was 15 at the time of presentation. No significant abnormal signs were detected on physical examination. Brain MRI was performed on day 21 post-trauma, which revealed a CSF intensity extra-axial lesion (arachnoid cyst) in left middle cranial fossa anterior to left temporal lobe (measuring $5 \times 3.7 \times 3.7 \mathrm{~cm}$ ) with evidence of mass effect over left temporal lobe. CSF intensity fluid was seen in the subdural space along left cerebral hemisphere, representing subdural hygroma with evidence of continuity with the mentioned middle cranial fossa arachnoid cyst (Fig. 1a-c). No other gross abnormality was noted in the cranial fossa. Images were also remarkable for mucoperiosteal thickening of right maxillary, frontal, ethmoid, and sphenoid sinuses. The diagnosis of ruptured left middle cranial fossa arachnoid cyst with subdural hygroma was made. As the patient was clinically well and there was no significant sign of original author(s) and the source, provide a link to the Creative Commons licence, and indicate if changes were made. The images or other third party material in this article are included in the article's Creative Commons licence, unless indicated otherwise in a credit line to the material. If material is not included in the article's Creative Commons licence and your intended use is not permitted by statutory regulation or exceeds the permitted use, you will need to obtain permission directly from the copyright holder. To view a copy of this licence, visit http://creativecommons.org/licenses/by/4.0/. The Creative Commons Public Domain Dedication waiver (http://creativeco mmons.org/publicdomain/zero/1.0/) applies to the data made available in this article, unless otherwise stated in a credit line to the data. 

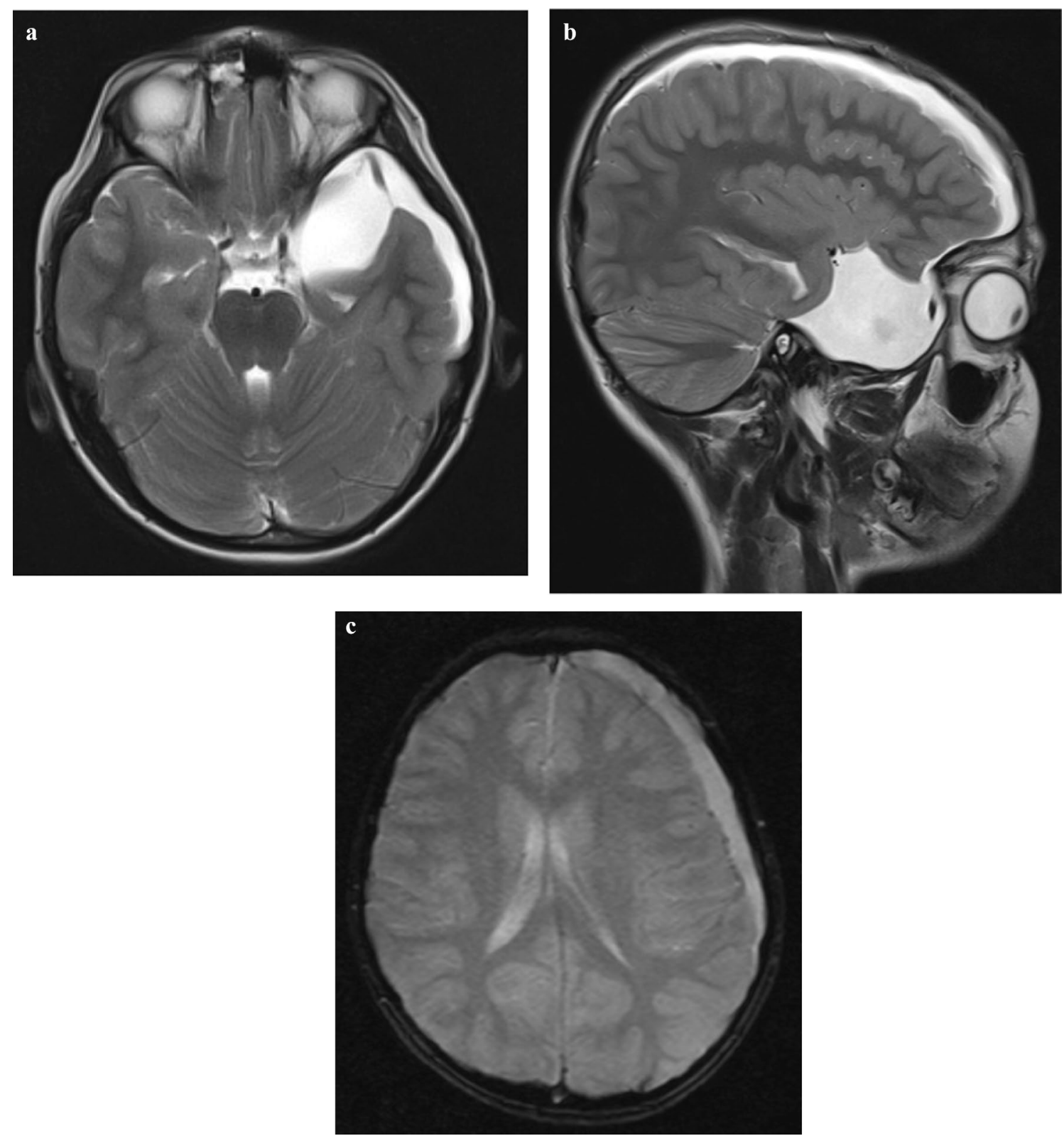

Fig. 1 a Axial T2WI through the temporal lobes: CSF intensity lesion in the left middle cranial fossa anterior to left temporal lobe with mass effect. There is evidence of discontinuity in the peripheral wall of the cyst (black arrow) with subdural fluid in the vicinity of the temporal lobe (white arrow). $\mathbf{b}$ Sagittal T2WI through the left temporal lobe: CSF intensity lesion in the left middle cranial fossa anterior to left temporal lobe with subdural fluid extending along the convexity of the left cerebral hemisphere. c Axial T2* gradient recalled echo (GRE) sequence through the frontal lobes: the subdural fluid shows no blooming artifact to suggest hemorrhage, hence confirming the collection is CSF intensity (hygroma)

increased intracranial pressure at the time of imaging, the patient was treated conservatively and the headache gradually disappeared completely over a 3 month period of follow-up.

\section{Case 2}

An ill-looking 15-year-old Afghan boy was brought to hospital complaining of vomiting, headache, and an episode of unconsciousness after head trauma in a road traffic accident 2 days ago. On physical examination, no abnormality was seen in the rest of the body system. No evidence of skull bruise or laceration was present. 
Brain CT scan revealed a CSF intensity extra-axial lesion (arachnoid cyst) in the right middle cranial fossa anterior to right temporal lobe (measuring $5 \times 5 \times 4 \mathrm{~cm}$ ) with evidence of atrophic changes of the temporal lobe and mass effect of the lesion. CSF intensity fluid $(\mathrm{HU}=10)$ was seen in the subdural space (subdural hygroma) along right cerebral hemisphere with evidence of continuity with arachnoid cyst (Fig. 2a-c). No intracranial hematoma, hemorrhagic contusion, or skull bone fracture was present. The diagnosis of ruptured right middle cranial fossa arachnoid cyst with subdural hygroma was made. The patient was referred to the neurosurgery department and was lost to follow-up.
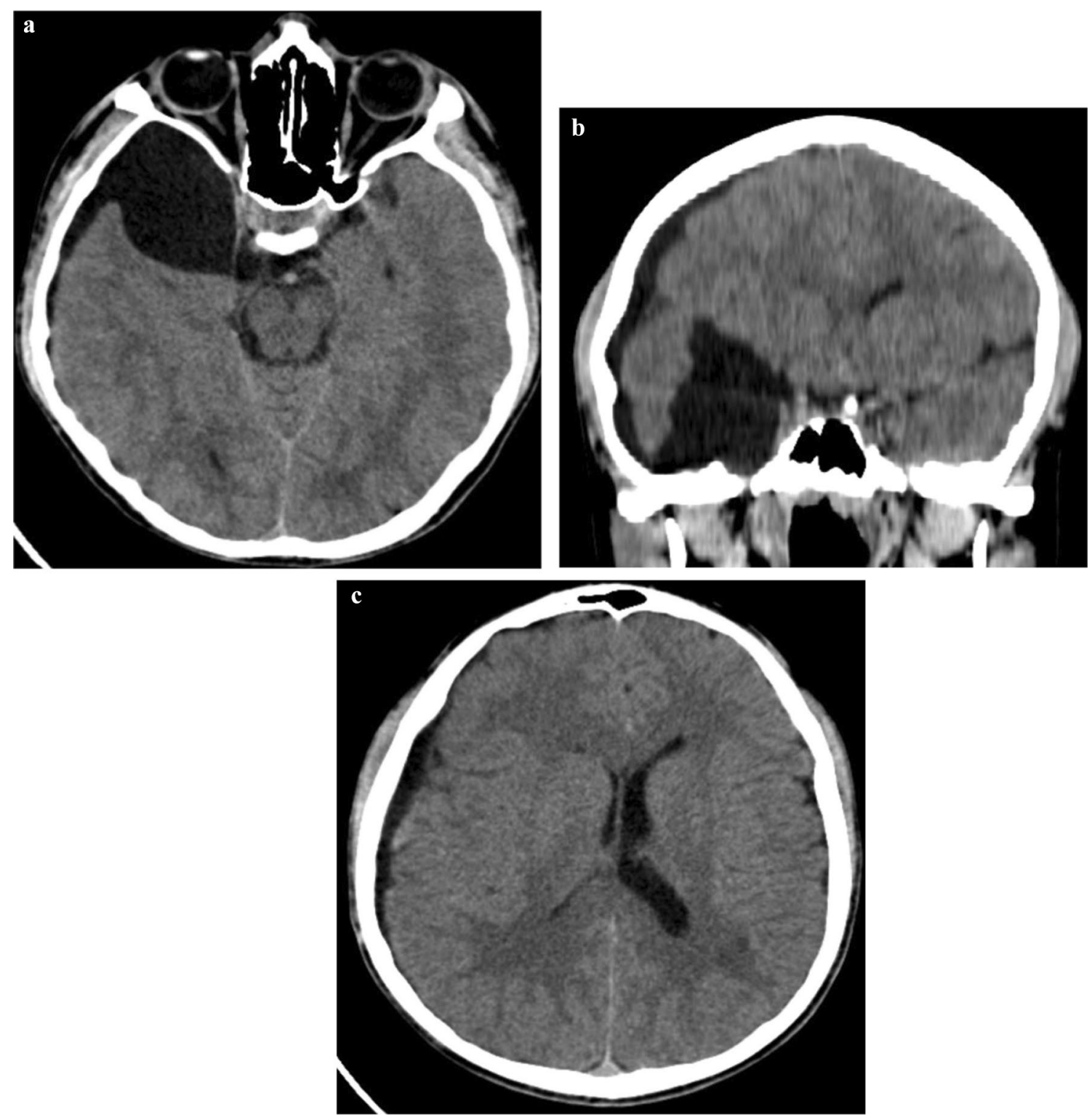

Fig. 2 a Axial CT section through the temporal lobes: CSF intensity lesion in right middle cranial fossa anterior to left temporal lobe with mass effect. There is communication with subdural fluid in the vicinity of the temporal lobe. $\mathbf{b}$ Coronal CT section through the temporal lobes: CSF intensity lesion in right middle cranial fossa with atrophic changes of right temporal lobe. There is subdural fluid extending along the right frontotemporal lobes with resultant mass effect, midline shift, and effacement of right lateral ventricle. c Axial CT section at the level of lateral ventricles: subdural fluid along the right cerebral hemisphere, with mass effect, effacing the right lateral ventricle, mild midline shift, and prominent left lateral ventricle 


\section{Discussion and conclusions}

IACs account for about $1 \%$ of all nontraumatic intracranial masses [1] with a predilection for male gender [2]. About $50-65 \%$ of IACs are located in the middle cranial fossa, more in the left side [2] (current cases were both in male patients; however, one was in the right and one in the left side). Other less common locations for intracranial arachnoid cysts are suprasellar cistern, quadrigeminal cisterns, cerebral convexities, cerebellopontine angles, and cisterna magna.

Middle cranial fossa IACs are often associated with variable degrees of temporal lobe agenesis and are classified into three types according to Galassi classification. Galassi type 1 cyst is small semicircular cyst confined to the anterior part of temporal fossa; type 2 is medium-sized, quadrangular cyst; and type 3 is large oval cyst with mass effect and midline shift [3]. The larger cysts are more likely to be symptomatic [4]. Symptoms can be generalized cranial enlargement, localized cranial bulging, increased intracranial pressure, seizures, psychomotor retardation, focal neurological deficits, hydrocephalus, and even dementia [5].

Occasionally, IACs may rupture-spontaneously or after trauma-and result in intracystic hemorrhage, subdural hematoma/subdural hygroma, or both [6], and may cause signs and symptoms of intracranial hypertension, mainly headache and vomiting [7]. Symptoms of IACs with subdural hygroma usually become increasingly severe for days or weeks after onset, but they eventually resolve [8].

A case-control study by Cress et al. on "risk factors for pediatric arachnoid cyst rupture/hemorrhage" demonstrated that children with larger intracranial arachnoid cysts (especially larger than $5 \mathrm{~cm}$ ) were at increased risk of cyst rupture. A head injury within the previous 30 days, even if considered relatively minor, was also associated with cyst rupture [9]. These complications may occur at any age and are reported with a wide range of patients, from as young as 12 months to adults 53 years old $[8,10]$.

Diagnosis Computed tomography (CT) and magnetic resonance imaging (MRI) can provide the diagnosis of arachnoid cyst and its complications. On CT, IACs appear as well-defined lesions, with the same density of the CSF. MRI can further differentiate between chronic subdural hematoma and hygroma, which CT cannot do.

Treatment and prognosis Treatment of asymptomatic IACs is a matter of controversy. Symptomatic cysts are treated surgically, while disappearance of arachnoid cysts has also been reported, both with and without a history of preceding trauma [11]. Again, in cases with surgical treatment, the selection of the best neurosurgical approach also remains controversial. The options include cyst shunting, craniotomy for cyst fenestration, endoscopic fenestration, deviation of cyst fluid to another intracranial space, and even cystoperitoneal shunting [12, 13].

Regarding the management of complicated arachnoid cysts to subdural collections, the best surgical treatment remains controversial due to the lack of reported cases [2]. Slaviero et al. reported two cases to suggest that surgical evacuation of the hematoma followed by an endoscopic cyst fenestration was a minimally invasive, safe, and effective approach for the treatment of middle cranial fossa arachnoid cysts complicated with subdural collections [2]. Maher et al. reported a series of eight patients with IACs and subdural hygroma, of which seven were managed without surgery and only one underwent surgery. All patients experienced complete resolution of presenting signs and symptoms; however, half of them had objective findings strongly correlated with elevated ICP including cranial nerve $(\mathrm{CN}) \mathrm{VI}$, palsy, papilledema, and progressive macrocephaly [8]. Hence, they disagreed with the idea that surgical treatment of subdural hygroma associated with arachnoid cysts is always, or almost always, necessary; instead, they suggested that the decision to surgically treat symptomatic hygroma associated with arachnoid cysts should be made carefully. They claimed that symptoms of elevated ICP are not an absolute indication for surgical treatment [8].

\section{Conclusion}

IACs are common, innocent, benign, usually incidentally detected intracranial lesions. They may rupture and complicate to subdural hematoma or hygroma after minor trauma. Imaging work-up is necessary for symptomatic patients following head trauma.

\section{Abbreviations}

IACs: Intracranial arachnoid cysts; MRI: Magnetic resonance imaging; CT: Computed tomography.

\section{Acknowledgements \\ None.}

Authors' contributions

Both authors have participated sufficiently in the submission and take public responsibility for its content. $\mathrm{FH}$ : writing the manuscript. $\mathrm{HH}$ : selecting the images and corresponding with the journal. Both authors read and approved the final manuscript.

\section{Funding}

No funding exists.

\section{Availability of data and materials}

Data sharing is not applicable to this article as no datasets were generated or analyzed during the current study (as this is a case report). 


\section{Declarations}

\section{Ethics approval and consent to participate}

The manuscript obtained ethical review exemption from the ethical review committee (ERC) of the authors' institution as case reports are exempt from review according to the institutional ethical review committee's policy. Written consent was obtained from the participants for publishing the case.

\section{Consent for publication}

Written informed consent was obtained from the patients' legal guardians fo publication of this case report and any accompanying images. A copy of the written consent is available for review by the Editor-in-Chief of this journal.

\section{Competing interests}

The authors declare that they have no competing interests.

\section{Author details}

${ }^{1}$ Neonatology Department, Maiwand Teaching Hospital, Kabul Medical University of Science (KMUS), Kabul, Afghanistan. ${ }^{2}$ Radiology Department, French Medical Institute for Mothers and Children (FMIC), Kabul, Afghanistan.

Received: 11 September 2020 Accepted: 1 September 2021 Published online: 12 October 2021

\section{References}

1. Goswami P, Medhi N, Sarma PK, Sarmah BJ. Case report: middle cranial fossa arachnoid cyst in association with subdural hygroma. Indian J Radiol Imaging. 2008;18(3):222.

2. Slaviero F, Frighetto L, Azambuja Júnior ND, Martins LS, Annes RD, Vanzin JR. Middle cranial fossa arachnoid cysts complicated with subdural collections. Arq Neuropsiquiatr. 2008:66(4):913-5.

3. Galassi E, Tognetti F, Gaist G, Fagioli L, Frank F, Frank G. CT scan and metrizamide CT cisternography in arachnoid cysts of the middle cranial fossa: classification and pathophysiological aspects. Surg Neurol. 1982;17:363-9.
4. Becker T, Wagner M, Hofmann E, Warmuth-Metz M, Nadjmi M. Do arachnoid cysts grow? A retrospective CT volumetric study. Neuroradiology. 1991:33:341-5.

5. Prabhu VC, Bailes JE. Chronic subdural hematoma complicating arachnoid cyst secondary to soccer-related head injury: case report. Neurosurgery. 2002;50:195-8.

6. Offiah C, Forbes WS, Thorne J. Non-haemorrhagic subdural collection complicating rupture of a middle cranial fossa arachnoid cyst. Br J Radiol. 2006;79:79-82.

7. Mori K, Yamamoto T, Horinaka N, Maeda M. Arachnoid cyst is a risk factor for chronic subdural hematoma in juveniles: twelve cases of chronic subdural hematoma associated with arachnoid cyst. J Neurotrauma. 2002;19:1017-27.

8. Maher CO, Garton HJ, Al-Holou WN, Trobe JD, Muraszko KM, Jackson EM Management of subdural hygromas associated with arachnoid cysts. J Neurosurg Pediatr. 2013;12(5):434-43.

9. Cress M, Kestle JR, Holubkov R, Riva-Cambrin J. Risk factors for pediatric arachnoid cyst rupture/hemorrhage: a case-control study. Neurosurgery. 2013;72(5):716-22.

10. Donaldson JW, Brown ME, Luerssen TG. Arachnoid cyst rupture with concurrent subdural hygroma. Pediatr Neurosurg. 2000;32:137-9.

11. Bilginer B, Onal MB, Oguz KK, Akalan N. Arachnoid cyst associated with subdural hematoma: report of three cases and review of the literature. Childs Nerv Syst. 2009;25(1):119-24.

12. Gupta R, Vaishya S, Mehta VS. Arachnoid cyst presenting as subdural hygroma. J Clin Neurosci. 2004;11(3):317-8.

13. Levy ML, Wang M, Aryan HE, Yoo K, Meltzer H. Microsurgical keyhole approach for middle fossa arachnoid cyst fenestration. Neurosurgery. 2003:53:1138-45.

\section{Publisher's Note}

Springer Nature remains neutral with regard to jurisdictional claims in published maps and institutional affiliations.

Ready to submit your research? Choose BMC and benefit from

- fast, convenient online submission

- thorough peer review by experienced researchers in your field

- rapid publication on acceptance

- support for research data, including large and complex data types

- gold Open Access which fosters wider collaboration and increased citations

- maximum visibility for your research: over $100 \mathrm{M}$ website views per year

At BMC, research is always in progress.

Learn more biomedcentral.com/submissions 